\title{
VALORES PESSOAIS ENVOLVIDOS NA ESCOLHA DE UM CURSO SUPERIOR: ANÁLISE UTILIZANDO A ABORDAGEM MEIO-FIM
}

\author{
PERSONAL VALUES INVOLVED IN CHOOSING \\ A COLLEGE: ANALYSIS USING THE \\ MEANS-END CHAIN APPROACH
}

Recebido 12-03-2012

Aceito 18-05-2013

Lilian Carolina Viana ${ }^{1}$

Cleiton Martis Duarte da Silva²

Kelly Carvalho Vieira ${ }^{3}$

Marcelo Ferreira Viana ${ }^{4}$

Luiz Henrique de Barros Vilas Boas ${ }^{5}$

\section{RESUMO}

A investigação dos motivos da escolha por produtos e serviços pelos consumidores destaca-se como relevante na área de estudos mercadológicos, bem como de apontamentos gerenciais para qualquer organização. Por meio da Teoria da Cadeia Meios-Fins proposta por Gutman (1982), a qual relaciona os "meios" (atributos e benefícios) ligados ao consumo de produtos ou serviços com os "fins" em termos de valores pessoais alcançados, é possível compreender melhor os significados que os consumidores atribuem durante a escolha de produtos e serviços em um nível mais abstrato. Desse modo, o objetivo deste estudo foi compreender que aspectos, considerando atributos, consequências e valores pessoais, norteiam o comportamento de estudantes no momento da escolha do curso de Enfermagem em uma Instituição de Ensino Superior privada. Tomando como base a teoria mencionada, adotou-se a técnica de entrevista em profundidade laddering e a metodologia de análise e representação do mapa hierárquico de valores, o qual foi interpretado e analisado visando compreender a estrutura cognitiva da escolha dos estudantes. As análises dos resultados indicam que os estudantes se pautaram, principalmente, por valores hedônicos de felicidade própria para a escolha do curso de Enfermagem na faculdade estudada.

Palavras-chave: Cadeias Meios-Fins; Valores Pessoais; Comportamento do Consumidor.

\footnotetext{
${ }^{1}$ Possui graduação e mestrado em Administração pela Universidade Federal de Lavras - UFLA. Atualmente é tutora à distância no curso de Administração Pública da Universidade Federal de Lavras - UFLA. Lavras, Minas Gerais, Brasil. E-mail: liliancviana@yahoo.com.br.

${ }^{2}$ Possui graduação em Administração pela Universidade Federal de Viçosa - UFV, mestrado em Administração pela Universidade Federal de Lavras - UFLA. Atualmente é no Instituto Federal de Educação, Ciência e Tecnologia de Minas Gerias - IFMG. Ouro Branco, Minas Gerais, Brasil. E-mail: cleitonduarte@yahoo.com.br.

${ }^{3}$ Possui graduação em Comunicação Social ela Pontifícia Universidade Católica de Minas Gerais - PUC/Minas. Atualmente é mestranda em Administração na Universidade Federal de Lavras - UFLA. Lavras, Minas Gerais, Brasil. E-mail: kellycarvalho1108@hotmail.com.

${ }^{4}$ Possui graduação em Enfermagem pelo Centro Universitário de Lavras - UNILAVRAS, mestrado em Administração pela Universidade Federal de Lavras - UFLA. Atualmente é doutorando em Administração na Universidade Federal de Lavras - UFLA. Lavras, Minas Gerais, Brasil. E-mail: mviana@unilavras.edu.br.

${ }^{5}$ Possui graduação em Agronomia pela Universidade Federal de Lavras - UFLA, mestrado e doutorado em Administração pela Universidade Federal de Lavras - UFLA. Atualmente é professor em Administração da Faculdade de Gestão e Negócios - FAGEN, da Universidade Federal de Uberlândia - UFU e Universidade Federal de Lavras - UFLA
} 


\section{ABSTRACT}

The investigation the reasons for choice of products and services by consumers stands out as relevant in the area of market studies, as well as notes management for any organization. Through the Theory of Means-End Chain proposed by Gutman (1982), which relates the "means" (attributes and benefits) linked to the consumption of products or services with the "ends" in terms of personal values achieved, it is possible understand of the meanings that consumers attribute the choice of products and services in a more abstract level. Thus, the objective of this study is to understand what aspects, considering attributes, consequences and personal values guide the behavior of students in choosing the nursing course at a private institution of higher education. Based on the theory mentioned it was adopted the technique laddering, in-depth interview and analysis methodology and representation of the hierarchical value map, which was interpreted and analyzed in order to understand the cognitive structure of students' choice.The analysis of the results indicate that students are guided primarily by hedonistic values of happiness itself the choice of nursing in college studied.

Keywords: Means-ends Chain, Personal Values, Consumer Behavior.

\section{INTRODUÇÃO}

O aumento da concorrência é observado em todo setor da economia, seja de produtos ou serviços, e isso não é diferente em Instituições de Ensino Superior (IES). Nos últimos anos, o número de IES cresceu em todo o país, sendo ainda maior o aumento do número de cursos e de vagas ofertadas tanto em instituições públicas quanto nas privadas. Essa expansão tem como fatores promotores os programas governamentais como Programa Universidade para Todos (Prouni), Sistema de Seleção Unificada (Sisu), Reestruturação e Expansão das Universidades Federais (Reuni) e Universidade Aberta do Brasil (UAB), que, de forma geral, visam facilitar o acesso à educação superior.

Conforme informações divulgadas no site do Ministério da Educação (MEC), a meta definida em 2008 foi dobrar o número de vagas nas universidades federais em 10 anos. Para isso, planeja-se aumentar o número de campus (que em 2002 era de 148 e em 2010 chegou a 274) para 321 até o fim de 2014. Da mesma forma, ocorre a expansão dos institutos federais, os quais também oferecem cursos de graduação (que somavam 140 campus em 2002), com a expectativa de atingir o número de 562 em 2014 (MEC, 2011).

Diante dessa crescente concorrência, é necessário que as instituições de ensino privadas elevem sua competitividade com a finalidade de atrair e de manter seus alunos, fazendo, para isso, uso do marketing a fim de identificar, dentre outras coisas, os fatores que influenciam a decisão dos potenciais compradores (MARTINS; TEIXEIRA; SILVA, 2009; DINIZ; CASTRO, 2010). Para tanto, uma forma de obter informações sobre seus consumidores é conhecer os valores pessoais que motivam e norteiam a decisão dos estudantes em relação a seus serviços. Para Pimenta et al. (2011), conhecer a estrutura cognitiva de valores dos consumidores possibilita o desenvolvimento de estratégias mercadológicas mais adequadas.

Além disso, esse tipo de estudo contribui para a compreensão da motivação de consumo com relação a um serviço educacional específico e, também, para o desenvolvimento teórico do marketing educacional no sentido da adequação da técnica e do entendimento dos valores pessoais. Isso ocorre uma vez que, segundo Ikeda e Veludo-de-Oliveira (2006), apesar do desenvolvimento de algumas definições teóricas em relação ao estudo do marketing de serviços, ainda é escassa a literatura que aborda a área educacional sob o enfoque de marketing, o que sugere a necessidade de uma abordagem teórica aplicada.

Nesse contexto, Reynolds e Gutman (1988) apresentam a Teoria de Cadeias de Meiosfins, segundo a qual o consumidor possui uma estrutura cognitiva de valores pessoais que orien- 
ta sua decisão de compra. Nessa perspectiva, Pimenta et al. (2011) afirmam que o consumidor percebe, nos produtos e serviços, atributos que lhes proporcionam consequências, entendidas como benefícios obtidos pelo uso, as quais são o meio para o alcance de valores, que podem ser compreendidos como estados finais almejados pelos consumidores. Assim, referem-se a uma hierarquia formada por atributos - consequências - valores (A-C-V) definida por Reynolds e Gutman (1988). Segundo os autores, a laddering é a técnica que melhor orienta a coleta, a análise e a interpretação dos dados na abordagem da Cadeia Meios-fim.

Nesse sentido, a questão proposta neste estudo foi: "quais os motivos levaram os acadêmicos a escolherem o curso de Enfermagem em uma determinada IES?". Desse modo, o objetivo geral desta pesquisa é compreender que aspectos, considerando atributos, consequências e valores pessoais, norteiam o comportamento de estudantes no momento de escolha pelo curso de Enfermagem em uma IES.

As instituições de ensino privadas têm o papel fundamental de ofertar serviços de educação por meio de cursos que, muitas vezes, não são oferecidos por universidades públicas, em atendimento, principalmente, às demandas regionais. Diniz e Castro (2010) ressaltam a importância dessas organizações particulares, que prestam serviços de ensino, pesquisa e extensão e precisam integrá-los à racionalidade de mercado. Esses autores também enfatizam que apenas recentemente as organizações de ensino superior passaram a ser objeto de estudo, contribuindo para o campo teórico. Considerando tais aspectos, optou-se por estudar uma IES privada, que atua no mercado há 44 anos, sendo amplamente conhecida em sua região de atuação.

Nesse sentido, escolheu-se o curso de Enfermagem pois: (i) não há na região oferta desse curso por nenhuma universidade pública; (ii) trata-se de um curso de acirrada concorrência entre instituições privadas de municípios na região; (iii) é um curso já consolidado historicamente na instituição em estudo; e (iv) é um curso que vem sofrendo queda na procura em função de fatores como desvalorização profissional, remuneração deficiente e mercado profissional saturado.

Para atingir esses objetivos, o trabalho estrutura-se da seguinte maneira: na seção 2, apresenta-se um referencial teórico que trata dos fatores influenciadores na escolha de uma IES, dos valores pessoais e da Teoria de Cadeia Meios-Fins; em seguida, na seção 3, descreve-se a metodologia e os procedimentos utilizados; na seção 4, são apresentados as análises dos resultados e as discussões; e, por fim, na seção 5, expõem-se as considerações finais.

\section{REFERENCIAL TEÓRICO}

\subsection{Fatores condicionantes na escolha da IES}

Pode-se definir a escolha profissional como o estabelecimento do que fazer, de quem ser e a que lugar pertencer no mundo por meio do trabalho (BOHOSLAVSKY, 1977). A formação da identidade profissional complementa a identidade pessoal e contribui para a integração da personalidade, de modo que uma boa escolha é avaliada pela forma como é tomada e pelas consequências cognitivas e afetivas que produz. A escolha envolve mudanças, perdas e medo do fracasso e da desvalorização (VEINSTEIN, 1994), supõe a elaboração de lutos e conflitos consigo e com os valores postos em jogo (BOHOSLAVSKY, 1977) e requer reavaliações constantes.

Ehrenberg e Smith (2000) também analisam a demanda por educação universitária na qual os indivíduos decidem frequentar uma universidade, por exemplo, por acreditarem que ela os deixará em uma situação melhor, ou seja, que fará com que receberão salários mais elevados. O ensino superior pode ser visto, ainda, apenas como um bem de consumo, com benefícios ime- 
diatos. Em curto prazo, o indivíduo pode apenas pensar na satisfação obtida com o estilo de vida estudantil. Contudo, visto como uma decisão em longo prazo, o ensino superior pode trazer outros benefícios, como a possibilidade de ter acesso a empregos mais valorizados e rendimentos mais altos ou de ter mais prestígio (status), tanto profissional quanto pessoal, no futuro.

Nesse aspecto, segundo Manes (1997), o marketing educacional consiste na investigação das necessidades sociais, com o objetivo de desenvolver serviços educacionais que satisfaçam tais necessidades, de acordo com seu valor percebido, distribuídos em tempo e lugar e eticamente promovidos para gerar bem-estar entre indivíduos e organizações. Conforme Cobra e Braga (2004), o marketing aplicado ao setor educacional objetiva identificar os principais grupos de consumidores desta categoria de serviços e suas necessidades de conhecimento para a formação profissional.

Nesse contexto, vale lembrar o que Churchill e Peter (2000, p. 4) destacam: que "a essência do marketing é o desenvolvimento de trocas em que organizações e clientes participam voluntariamente de transações destinadas a trazer benefícios para ambos". O marketing educacional está baseado em serviços, uma categoria bastante susceptível para a administração. Os serviços possuem características que os tornam mais sensíveis às pequenas variações no seu fornecimento em relação à percepção dos usuários. Para Lovelock (1983), o serviço educacional classifica-se como um serviço de ações intangíveis, focado na mente das pessoas, de entrega contínua, realizado por meio de uma parceria entre a organização de serviço e seu cliente, e, apesar de proporcionar um alto contato pessoal, é de baixa customização.

Nessa perspectiva, no entanto, Cobra e Braga (2004) fazem considerações sobre a aplicação desse modelo nos serviços educacionais, afirmando que estes são simultaneamente intangíveis e tangíveis, cuja mensuração depende dos alunos, mas é heterogêneo em função da individualidade de cada aluno; é perecível porque o prazo de validade do conhecimento é curto e simultâneo, uma vez que o desenvolvimento e o consumo do conhecimento ocorrem ao mesmo tempo. Isso significa que, em uma sala de aula, pode haver alunos que avaliem positivamente um determinado professor enquanto outros o avaliem negativamente sobre um mesmo serviço prestado.

Lautenborn apud Kotler (2000) sugere o modelo dos quatro "4C's" - Cliente, Conveniência, Comunicação e Custo. Sob essa ótica, é importante ter um cliente para vender o serviço, oferecer-lhe conveniências para retê-lo, seduzi-lo por meio da comunicação e oferecer o serviço a um custo que esteja dentro de suas possibilidades e expectativas.

Trazendo este modelo para o marketing educacional, observa-se o aluno como cliente; o acesso à escola, os estacionamentos, as lanchonetes, os espaços de integração, entre outros como conveniências; o professor-comunicador como comunicação; e o valor cobrado pelo produto/serviço, os investimentos em biblioteca, entre outros como custos (COBRA; BRAGA, 2004).

Nesse sentido, no campo educacional, a instituição moderna está disposta a oferecer e trocar valores com diferentes participantes, incluindo seus próprios alunos, de modo a obter sua cooperação e, assim, atingir as metas organizacionais (KOTLER, 1994). Para Cobra e Braga (2004, p. 126), "a estratégia de marketing é uma extensão da implementação das estratégias corporativas e de negócios". Para tanto, é necessário que as instituições educacionais se voltem para o mercado e para os fatores condicionantes de escolha dos clientes pelas IES, baseados muitas vezes nos valores pessoais, a fim de se manterem competitivas e estabelecerem relacionamentos agradáveis e duradouros para que haja demanda contínua aos serviços. Oliveira, Tavares e Sato (2010) afirmam que essas informações são essenciais para tomada de decisões de marketing.

Essa discussão perpassa pelo conceito de comportamento do consumidor que, conforme se discute, diz respeito ao estudo dos consumidores, bem como do processo que realizam para selecionar, obter e comprar produtos, serviços e ideias que satisfaçam suas necessidades 
(OLIVEIRA; TAVARES; SATO, 2010). Portanto, torna-se fundamental a compreensão dos valores pessoais que influenciam o comportamento do consumidor, o que será discutido a seguir.

\subsection{Valores Pessoais}

Os valores humanos são um importante instrumento de análise que descrevem e explicam as semelhanças e divergências entre pessoas, grupos e culturas (ROKEACH, 1981). Schwartz e Bislky (1987) conceituam os valores pessoais como crenças que se referem a estados psíquicos, situações desejadas ou comportamentos, capazes de condicionar os indivíduos na seleção ou avaliação de comportamentos ou eventos. Um valor é uma crença duradoura que raramente se modifica na vida adulta, e valores pessoais são metas desejáveis que variam em importância e guiam a vida das pessoas. Segundo Rokeach (1981), os valores são ordenados conforme sua importância relativa. Nessa perspectiva, Gutman (1982) enfatiza que as consequências e os valores que movem os consumidores são fatores de persuasão que influem o comportamento do consumidor.

Com o propósito de verificar os principais valores orientadores da conduta humana, Schwartz e Bislky (1987) apresentaram uma escala composta por 56 valores humanos (Escala de Valores de Schwartz), baseados nas necessidades humanas universais: as necessidades biológicas básicas, as necessidades de coordenação social e os requisitos para o bom funcionamento dos grupos sociais. Essa escala foi testada em 67 países (TAMAYO; PORTO, 2005).

A escala de Schwartz indica uma estrutura com 10 fatores motivacionais: 1) Poder - busca da preservação de uma posição social dentro de um sistema social; 2) Autorrealização - busca do sucesso pessoal por meio da demonstração de competência de acordo com as regras sociais; 3) Hedonismo - busca de prazer e gratificação para si mesmo; 4) Estimulação - busca de novidade e estimulação na vida; 5) Autodeterminação - busca de independência de pensamento e ação; 6) Universalismo - compreensão e proteção do bem-estar de todos e da natureza; 7) Benevolência - preocupação com o bem-estar de pessoas próximas; 8) Tradição - respeito, compromisso e aceitação dos costumes e das ideias de uma cultura ou religião; 9) Conformismo - restrição de ações e impulsos que podem magoar os outros ou violar as expectativas sociais e normas; e 10) Segurança - busca de segurança, harmonia e estabilidade da sociedade e dos relacionamentos.

Segundo Schwartz (1992), uma vez que entre os 10 tipos motivacionais podem surgir conflitos, eles são agrupados em dimensões bipolares. Dessa forma, por exemplo, tem-se autotranscendência versus autopromoção: o poder e a conquista opõem-se a valores como universalismo e benevolência; abertura à mudança versus conservadorismo: valores como auto-orientação e estímulo opõem-se a valores de conformidade e tradição.

Considerando a intenção de compreender os aspectos atributos, consequências e valores pessoais, que nortearam o comportamento de estudantes de Enfermagem no momento de escolha por uma instituição de ensino, a estrutura proposta por Schwartz foi utilizada como referência para o desenvolvimento desta pesquisa.

\subsection{Teoria de Cadeias Meios-Fins}

Ao buscar compreender o significado que os consumidores atribuem aos produtos e serviços que consomem, pesquisadores buscam entender o comportamento dos clientes e os valores pessoais que os orientam. Segundo Ikeda e Veludo-de-Oliveira (2005), alguns modelos teóricos foram propostos para alcançar esse fim, como o de Young e Feigin (1975), Vinson, Scott e Lamont (1977) e Howard (1977), servindo de base para a teoria de Gutman (1982) - a Teoria de 
Cadeias Meios-Fins -, em que se baseia o presente artigo.

A Teoria de Cadeias Meios-Fins diz respeito ao processo de categorização que relaciona os "meios" ligados ao consumo de produtos ou serviços com os "fins" em termos de valores pessoais. Esse modelo pode fornecer uma base para aumentar nossa compreensão de como os consumidores cognitivamente definem conjuntos competitivos de produtos (GUTMAN, 1981).

Uma investigação macro não fornece um entendimento específico de como os aspectos concretos do produto se encaixam na vida do consumidor, permitindo adquirir apenas parte da resposta. A perspectiva mais psicológica oferecida por uma abordagem "micro", baseada na teoria meios-fins, concentra-se especificamente sobre as relações entre os atributos que existem nos produtos (os "meios"), os quais fornecem as chamadas consequências, e os valores pessoais por sua vez, reforçam essas relações como elo final entre atributos - consequências - valores (REYNOLDS; GUTMAN, 1988). Desse modo, para Gutman (1981), "meios" são objetos (produtos) ou atividades com que as pessoas se envolvem, ligados às extremidades chamadas de "fins", tal como felicidade, segurança, realização etc. A cadeia de meios-fins é definida como sendo composta de um conjunto interligado de elementos cognitivos que permitem uma pessoa escolher objetos ou atividades que lhe possibilitem alcançar o estado final desejado (GUTMAN, 1981).

Diversos estudos, como o de Borges et al. (2012), Leão e Mello (2003), Pimenta e Vilas Boas (2008) e Pinese e Moriguchi (2012), utilizam a teoria da cadeia meios-fins, discutindo sua relevância gerencial como um método para compreender os valores dos consumidores que compram determinado produtos, marcas ou serviços. Outros estudos partem da perspectiva educacional para identificar os valores de escolha dos serviços educacionais, como o de Costa e Oliveira (2008), Nogueira et al. (2012), Rezende, Caixeta e Moriguchi (2010), Veludo de Oliveira e Ikeda (2006) e Vilas Boas et al. (2012).

Realizam-se, portanto, vínculos entre atributos, benefícios de produtos e valores dos consumidores, o que permite a resolução de um grupo amplo de problemas da área de marketing, incluindo desenvolvimento de novos produtos, posicionamento de marca, estratégias de propaganda e segmentação de mercado (VILAS BOAS et al. 2005). Para Gutman (1982), essa teoria tem um lugar central no planejamento de marketing e pesquisa do consumidor, já que os conceitos da Teoria de Cadeias Meios-Fins oportunizam uma maneira de posicionar os produtos, devido à publicidade que visa amarrar o consumo desses produtos para a realização de fins desejados. Saber, por exemplo, que consumidores querem estar bem vestidos não diz muito, a menos que se descubra o motivo pelo qual eles querem isso (atratividade sexual, realização, higiene etc.) e quais os atributos na roupa estão associados a estar bem vestido. Por isso, os elementos que compõem as cadeias meiosfins e suas conexões devem ser operacionalizados de forma a facilitar a pesquisa, possibilitanto $o$ entendimento da relação atributo-valor na perspectiva dos consumidores.

O modelo, segundo Gutman (1982), baseia-se em dois pressupostos fundamentais sobre o comportamento do consumidor: (1) que os valores, definidos como desejáveis estados finais de existência, desempenham um papel dominante na orientação dos padrões de escolha e (2) que as pessoas lidam com a enorme diversidade de produtos que são de satisfação potencial de seus valores, agrupando-os em conjuntos ou classes, de modo a reduzir a complexidade da escolha. Além dessas duas hipóteses sobre o comportamento do consumidor, que são essenciais para a forma particular do modelo, existem dois outros pressupostos de natureza mais geral. Essas suposições são a de que todas as ações dos consumidores têm consequências (embora nem todos os consumidores concordem que as mesmas ações nas mesmas situações produzam as mesmas consequências) e de que os consumidores aprendem a associar consequências especiais com ações particulares (GUTMAN, 1982). 
O modelo fornece uma estrutura teórica capaz de fazer a conexão entre os valores dos consumidores e seus comportamentos. O modelo de cadeias meios-fins aponta três níveis de associações, que partem de atributos dos produtos ou serviços (A) para consequências (C) e de consequências para valores pessoais (V), formando, assim, a sequência A-C-V. Portanto, a cadeia meios-fins enfatiza a razão e o modo pelo qual os atributos dos produtos são importantes, indo além do entendimento de suas propriedades funcionais, pois visa compreender seus significados na vida do cliente (IKEDA; VELUDO DE OLIVEIRA, 2005).

Segundo Gutman (1982, p. 61), consequências são definidas como "qualquer resultado (fisiológico ou psicológico) provenientes, direta ou indiretamente, ao consumidor (cedo ou tarde) de seu comportamento". As consequências podem ser desejáveis ou indesejáveis. As desejáveis seriam os chamados benefícios, que, de acordo com o autor, são as vantagens que os consumidores desfrutam ao consumir um produto ou serviço. Portanto, os benefícios são consequências desejáveis que diferem dos atributos, pois as pessoas recebem benefícios dos produtos, que, por sua vez, possuem atributos.

Quanto à sequência $A-C-V$, a ligação entre consequências e valores é um dos elos básicos do modelo. À medida que os valores são ordenados conforme prioridade dão importância às consequências. Um ato de consumo, portanto, deve ocorrer para que as consequências desejadas sejam realizadas. Assim, uma escolha entre produtos alternativos tem de ser feita. A fim de fazer essa escolha, o consumidor deve saber quais produtos possuem atributos que irão produzir as consequências desejadas e os valores pessoais percebidos (GUTMAN, 1982).

Para Gutman (1991), muitas consequências são mais imediatamente relacionadas com a escolha do consumidor do que com seus valores pessoais. $O$ autor sugere que é preciso haver alguns passos intermediários para explicar como os valores se relacionam com a escolha do consumidor. Por isso, conforme desenvolvido por Reynolds e Gutman (1988), a aplicação mais comum da Teoria da Cadeia De Meios-Fins em marketing passa pela seguinte hieraquia: 1) atributos concretos dos produtos; 2 ) atributos abstratos dos produtos; 3 ) consequências percebidas do consumo; 4) consequências psicológicas dos produtos; e 5) valores terminais percebidos ou imaginados, estados finais resultantes do consumo da classe de produtos (VILAS BOAS et al., 2005).

Para uma melhor sequência, Gutman (1981) aborda o processo chamado de categorização como o mecanismo pelo qual os consumidores organizam o pensamento sobre as alternativas de produtos ou serviços específicos. Por isso, grupos ou categorias de produtos (classes de produtos, por exemplo) têm de ser sistematicamente relacionados às extremidades de nível superior da cadeia e servir à sua finalidade instrumental de permitir que a pessoa atinja seus valores.

Segundo Gutman (1982), as formas pelas quais os consumidores descrevem a diversidade funcional na escolha de produtos e serviços pode dizer muito sobre suas cadeias meios-fins. A sequência $A-C-V$ pressupõe uma série de atributos, consequências e valores que são assimetricamente ligados pelo entrevistado, segundo o qual o "nível inferior" dos elementos leva ou implica um "nível superior" (GUTMAN, 1991). Por isso, os níveis de abstração, conforme Olson e Reynolds (1983) citados por Gutman (1991), sugerem uma ordenação entre os elementos de tal forma que há um "caminho certo" a ser seguido para as relações estabelecidas. Assim, atributos produzem consequências; e, em relação às consequências, consequências funcionais produzem consequências sociais e estas produzem satisfação de valor. Nesse sentido, Vilas Boas et al. (2005) afirmam que a Teoria de Cadeias Meios-Fins procura estabelecer que, quanto mais abstrato é o nível de informação obtido, mais direta e representativa se torna esta informação com o indivíduo consumidor e sua real relação com o produto e a ação de compra, pois os níveis mais abstratos de conhecimento representam níveis mais concretos de significados com o consumidor. 
O modelo tem a vantagem de que o consumidor pode apontar os critérios a serem utilizados no consumo de produtos/serviços, de tal forma que esses critérios apresentem ligações entre os aspectos físicos (que podem oferecer uma visão enganosa da perspectiva do consumidor em relação aos produtos) e os benefícios percebidos com a aquisição desses produtos/ serviços pelos consumidores, que, por sua vez, se esforçam para encontrar valores no consumo (GUTMAN, 1981). A premissa comum, então, é que os consumidores aprendem a escolher os produtos que contêm atributos fundamentais para alcançar as consequências desejadas. A Teoria de Cadeias Meios-Fins simplesmente especifica a lógica subjacente com base nas consequências importantes, ou seja, nos valores pessoais (REYNOLDS; GUTMAN, 1988).

\section{METODOLOGIA}

Este estudo é de natureza qualitativa, uma vez que se propõe a conhecer a realidade individual relacionada ao comportamento de estudantes no momento de escolha da instituição de ensino. Para alcançar o objetivo proposto, optou-se pela abordagem qualitativa porque, conforme afirmam Carapara e Ladin (2008), os métodos de estudos qualitativos assumem cada vez mais relevância dado a grande necessidade de instrumentos que valorizem o ponto de vista do indivíduo pesquisado.

Entre os diversos métodos possíveis nas ciências sociais, a técnica de entrevista utilizada nesta pesquisa foi a laddering. Assim como toda teoria requer metodologias para a sua aplicação, a laddering e o mapa hierárquico de valores (Hierarchical Value Map - HVM) são as técnicas de entrevista em profundidade e metodologia de análise e representação mais adequadas à Teoria de Cadeias Meios-Fins, segundo Vilas Boas et al. (2005).

A laddering envolve um formato adaptado de entrevista que utiliza, principalmente, uma série de questões dirigidas, tipificada pela questão principal: "Por que é tão importante para você?", com o objetivo expresso de determinar os conjuntos de ligações entre os elementos-chave de percepção em toda a gama de atributos (A), consequências (C) e valores (V). A análise dos dados pela laddering envolve resumos de elementos-chave por padrão de análise de conteúdo, tendo em mente os níveis de abstração A-C-V (REYNOLDS; GUTMAN, 1988).

Dessa forma, percebe-se que o objetivo da laddering é identificar o conteúdo e a sequência (ou estrutura) dos resultados decorrentes de comportamentos de escolha, que se estendem, a partir dos atributos possuídos pelo objeto, por meio das consequências para atingir os valores pessoais. Essa técnica, assim como outras abordagens em profundidade, depende da interação entre o entrevistador e o entrevistado, pois não é fácil deixar que o entrevistado determine os encadeamentos A-C- $V$ independentemente do entrevistador. Frequentemente, o entrevistado irá determinar associações simples de A-C-V; porém, tais respostas não produzem o tipo de dados para construir mapas de estrutura hierárquica. A laddering se concentra-se, portanto, em determinar as associações de encadeamento (GUTMAN, 1991).

Vilas Boas et al. (2005) resumem três passos para o desenvolvimento da técnica laddering, que foram realizados nesta pesquisa: 1 ) identificar atributos salientes - questionar os consumidores quanto aos atributos usados para comparar e avaliar produtos/serviços em questão; 2) entrevista em profundidade - os principais atributos identificados na primeira parte são utilizados como ponto de partida da entrevista em profundidade, de modo que a pergunta "por que o atributo... é importante para você?" força os entrevistados a elevarem o nível de abstração em suas respostas (ao final, não necessariamente se alcança o nível de valor, sendo o resultado uma sequência de conceitos, chamados escalas); e 3) análise dos resultados - os conceitos idiossincráticos resultantes das entrevistas são categorizados em um pequeno número de categorias. 
Assim, utilizando a técnica laddering, realizaram-se 18 entrevistas em profundidade com estudantes do curso de Enfermagem da Faculdade Beta (nome fictício), privada e localizada no interior de Minas Gerais. Esses estudantes se encontravam matriculados em períodos diversos do curso. As entrevistas foram feitas no ambiente escolar, facilitando a comunicação entre pesquisadores e respondentes. Os entrevistados foram selecionados de duas formas: por conveniência, os estudantes que se encontravam na biblioteca ou no pátio da faculdade e aceitaram participar da pesquisa; ou por indicação de professores da faculdade, casos em que foi agendado com o estudante o momento da entrevista.

Todas as entrevistas foram gravadas em áudio, transcritas e posteriormente analisadas para o processo de agrupamento de sinônimos e atribuição de códigos de resumo. Na realização das entrevistas, seguiram-se os pressupostos e passos indicados por Reynolds e Gutman (1988) para execução do método laddering. Os respondentes foram questionados quanto à preferência em relação ao serviço (curso de Enfermagem na Faculdade Beta). Na maioria das entrevistas, utilizou-se o método das diferenças de preferência de consumo. Depois de listados os atributos, estes eram confirmados com o entrevistado. Delimitou-se por explorar, no máximo, três atributos em cada entrevista. Nos casos em que surgiram mais atributos, aos consumidores foi solicitado que definissem os três mais importantes.

$\mathrm{Na}$ etapa seguinte, realizou-se a entrevista em profundidade quando se questionou aos estudantes o motivo da importância de cada um dos atributos e consequências apontados. Durante a pesquisa, problemas comuns a esse tipo de entrevista surgiram, como momentos em que o entrevistado não sabia a resposta, ou seja, momentos em que o estudante não sabia o porquê de determinado atributo ou consequência ser importante para ele. Gerou-se, então, uma barreira, com uma racionalização da resposta, que passa a não retratar a realidade. Tais situações são conhecidas por "estruturas cognitivas estratégicas". Para esses casos, considera-se as orientações de Reynolds e Gutman (1988): a) questionar situações com a ausência do objeto; b) alterar o questionamento dentro de determinado contexto; c) solicitar alguma situação que o consumidor vivenciou contendo ou não o atributo ou os benefícios; d) transferir o questionamento para a terceira pessoa; e) ficar em silêncio; e f) checar a comunicação, em que é repetida a pergunta ao entrevistado ou questionado o conceito de algo dito pelo mesmo. Em alguns casos, os próprios respondentes utilizam essas técnicas, como quando começam a responder na terceira pessoa. Todas essas técnicas foram utilizadas com a finalidade de ultrapassar algum bloqueio ou barreira e, assim, viabilizar a continuidade do raciocínio pelo entrevistado de forma a elevar o nível de abstração.

Após transcritas e atribuídos os códigos resumos para as respectivas cadeias A-C-V, uma tabela denominada Matriz de Implicação foi construída, representando o número de ligações entre os conceitos. Segundo Reynolds e Gutman (1988), é a partir desse quadro resumo que conexões dominantes podem ser representadas graficamente em um diagrama de árvore, chamado de Mapa de Valor Hierárquico (HVM - Hierarchical Value Map).

Este é o terceiro passo, que consiste no objetivo final da técnica laddering. É a partir da estrutura do mapa hierárquico de valores que se realiza a análise que resultará na identificação das orientações de percepção dominantes. Esse tipo de mapa cognitivo é de natureza estrutural e possibilita uma interpretação mais fácil acerca dos valores de um grupo de consumidores e das conexões ou cadeias [atributos-consequências-valores] mais intensas e importantes para compreensão do fenômeno (REYNOLDS; GUTMAN, 1988). As informações obtidas foram analisadas por meio do software MecAnalyst. 


\section{ANÁLISE E DISCUSSÕES}

A interpretação e análise dos dados obtidos por meio da laddering foram realizadas conforme os procedimentos descritos por Reynolds e Gutmam (1988). Os resultados são apresentados na Tabela 1, de forma sistemática, incluindo os elementos da Cadeia Meios-Fins identificados nesta pesquisa e seus respectivos códigos.

Tabela 1 - Codificação e categorias identificadas na análise de conteúdo.

\begin{tabular}{|c|l|c|l|}
\hline \multicolumn{6}{|l|}{ Códigos Resumos: Atributos, Consequências e Valores } \\
\hline Cód. & ATRIBUTOS & Cód. & CONSEQUÊNCIAS \\
\hline 1 & Nome e estrutura da faculdade & 17 & Maior aprendizado \\
\hline 2 & Próximo a minha casa & 18 & Base profissional \\
\hline 3 & Indicação e referências de outras pessoas & 19 & Confiança/segurança \\
\hline 4 & Experiência em cuidar de doentes & 20 & Não perder tempo \\
\hline 5 & Curso muito bom & 21 & Ajudar da melhor forma \\
\hline 6 & A grade curricular & 22 & Medo \\
\hline 7 & Trabalho mais humanizado & 23 & Levar a sério \\
\hline & & 24 & Confirmou as indicações \\
\hline Cód. & CONSEQUÊnCIAS & 25 & Prática \\
\hline 8 & Arrumar emprego & 26 & Reconhecimento dos pacientes \\
\hline 9 & Ser competente & & \\
\hline 10 & Busca ser melhor sempre & Cód. & VALORES \\
\hline 11 & Uma boa profissional & 27 & Feliz comigo mesmo \\
\hline 12 & Incentivada e elevada autoestima & 28 & Prazer \\
\hline 13 & Aprender a conversar com as pessoas & 29 & Uma vida mais feliz \\
\hline 14 & $\begin{array}{l}\text { Ter bons professores e oportunidades de es- } \\
\text { tágio }\end{array}$ & 30 & Se sentir mais preparado para atuar \\
\hline 15 & Questão financeira & 31 & Realização \\
\hline 16 & Família & & \\
\hline
\end{tabular}

Fonte: Elaborado pelos autores.

O mapa hierárquico de valores (Figura 1), construído por meio do software MECanalyst, demonstra, de forma agregada, quais atributos, consequências e valores foram identificados na pesquisa, bem como as relações mais representativas verificadas entre os elementos a partir de um ponto de corte determinado de forma a representar em média dois terços de todas as relações da matriz (REYNOLDS; GUTMAN, 1988).

Como pode ser verificado nas relações apresentadas no mapa (Figura 1), percebe-se que o sentido da cadeia meios-fins é da base para topo. Na base do mapa, estão presentes os atributos: nome e estrutura da faculdade; próximo a minha casa; indicação e referência de outras pessoas; e curso muito bom. Na região central, estão as consequências: arrumar emprego; ser competente; ter bons professores e oportunidade de estágio; questão financeira; família; maior aprendizado; base profissional; sentir confiança e segurança; e não perder tempo. Já os valores ocupam lugar no topo da hierarquia: feliz comigo mesmo; realização; e vida mais feliz. 
Figura 1 - Mapa hierárquico de valores.

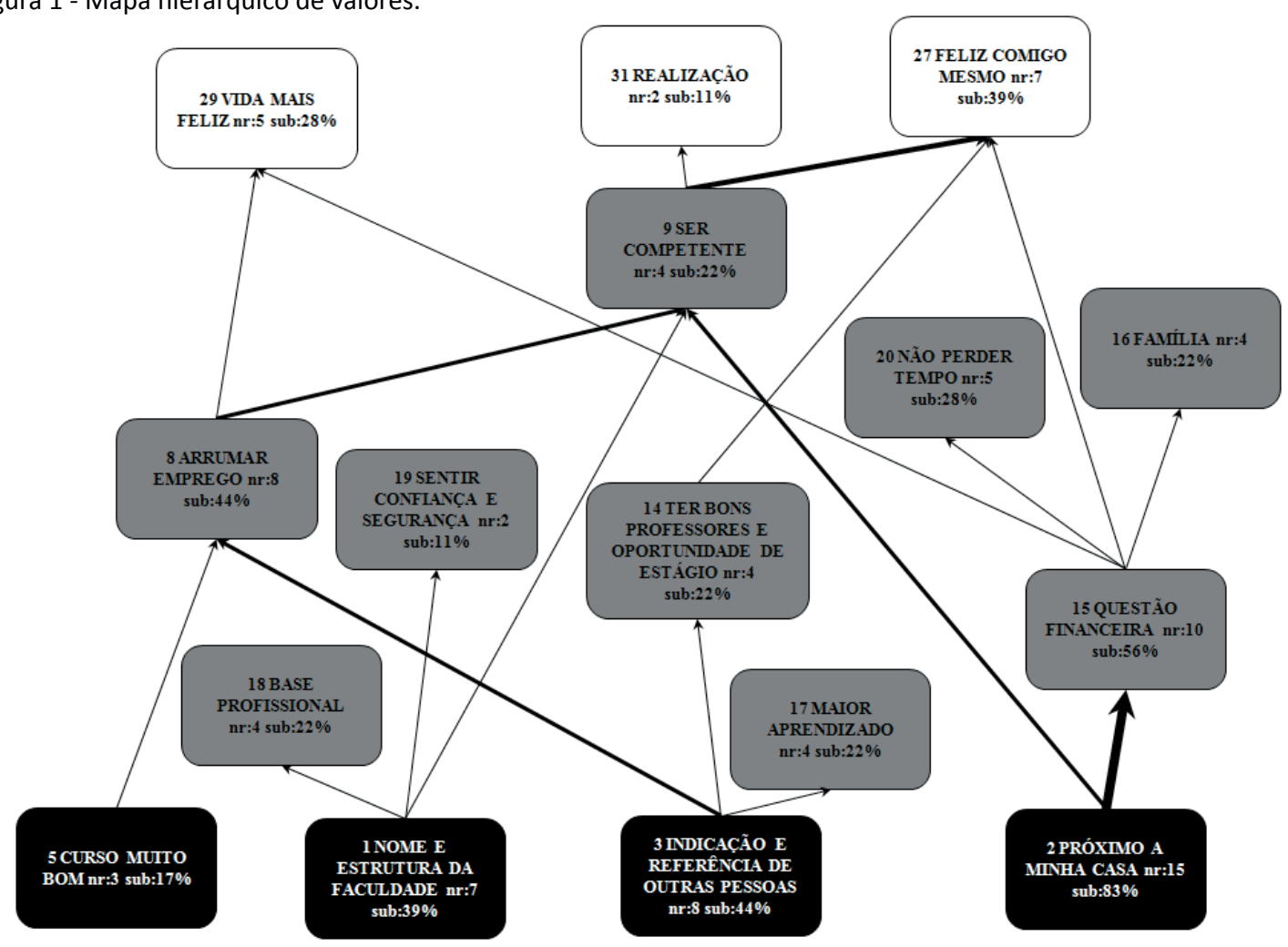

Fonte: Elaborado pelos autores.

Uma importante função do mapa hierárquico de valores é fornecer informações para a identificação das cadeias dominantes, ou seja, aquelas que apresentam o maior número de relações diretas e indiretas e que são consideradas as mais representativas nas orientações de percepção entre os respondentes. No caso deste estudo, as cadeias dominantes são aquelas que apresentam as setas em destaque no mapa: quanto mais espessa é a seta, mais forte pode ser considerada a conexão entre os elementos da cadeia; e quanto maior o ponto de corte, maior nível de significância do mapa (neste trabalho, o ponto de corte utilizado foi 2). O que determina o ponto de corte é a representatividade no mapa quanto ao número de relações a partir da matriz de implicação.

Diante das informações contidas no mapa hierárquico de valores (HVM), são identificadas algumas orientações de percepção, tomando como referência as cadeias desenvolvidas. Para análise, ressaltam-se as cadeias dominantes por serem consideradas as mais importantes. O entendimento dessas cadeias pode justificar a preferência de escolha do curso de Enfermagem na instituição pesquisada. Destaca-se no mapa a sequência (A-C-V) que parte do atributo (A) "próximo a minha casa" para (C) "ser competente" e para (V) "feliz comigo mesmo". Pode-se perceber que o fato de a faculdade ser próxima à casa dos estudantes, estando localizada na mesma cidade ou em uma cidade próxima, faz com que eles tenham mais conhecimento a respeito da faculdade, seja pela propaganda que a universidade realiza na região, seja por terem conhecidos, amigos e familiares que se formaram no estabelecimento. Tal conhecimento leva-os a ter segurança na escolha da faculdade; e essa segurança e comodidade culminam em uma oportunidade de que possam ser competentes nos estudos e na profissão escolhida, propiciando-lhes o valor de felicidade consigo mesmo. Nesse sentido, percebe-se a ligação com a teoria antes revisada, de modo que a escolha pelo curso na universidade está ligada ao lugar a que pertencem. Segundo Veinstein (1994), quando o consumidor diz que a escolha leva ao medo e a mudanças, isso está 
ligado ao fato de que a mudança de cidade e a separação da família é de tal importância que impacta diretamente na própria felicidade.

Outra sequência (A-C-C-V) de destaque é a seguinte: $(A)$ "indicação e referência de outras pessoas" - (C) "arrumar emprego" - (C) "ser competente" - (V) "feliz comigo mesmo". Por essa sequência, percebe-se que o fato de conhecer outras pessoas que já estudaram na faculdade, ex-alunos (parentes e amigos, ou seja, pessoas representativas) e professores, vai de encontro à certeza de que os que passaram pela instituição tiveram uma alocação profissional. Ou seja, ao realizar o curso de Enfermagem na instituição pesquisada, a chance de alcançar um emprego é grande. Os entrevistados acreditam que, a partir dessas relações, será possível alcançar a competência necessária e estarem preparados para o mercado de trabalho. Desse modo, atingiriam a felicidade consigo mesmo.

Na cadeia supracitada, nota-se, primeiramente, o quanto o marketing boca a boca de ex-alunos e atuais é, de fato, determinante para a escolha dos estudantes. Além disso, percebe-se que a decisão por uma faculdade está relacionada a uma consequência de longo prazo, o que Ehrenberg e Smith (2000) atribuem ao fato de os universitários acreditarem que a faculdade os deixará em uma situação melhor, ou seja, que receberão salários mais elevados. Isso é confirmado na cadeia em questão com as consequências "ser competente" e "arrumar emprego", resultados que estão em conformidade com Bohoslavsky (1977), indicando que a escolha da instituição influenciará em toda a vida profissional.

É possível perceber que ambas as cadeias dominantes citadas passam pela consequência "ser competente" e pelo valor "feliz comigo mesmo". Ser competente na visão dos entrevistados significa saber lidar com situações diversas e ter a facilidade de se manter no emprego, o que os leva ao valor pessoal de felicidade consigo, por serem capacitados para realizar o trabalho. Tendo em vista a escala de Schwartz, o valor "felicidade comigo mesmo" identificado nas entrevistas demonstra a busca de prazer e gratificação para si mesmo, o que é chamado pelo autor de hedonismo.

Cabe destacar a forte ligação encontrada entre (A) "próximo a minha casa" e (C) "questão financeira", o que se deve à economia e facilidade que os entrevistados expuseram em estudar na mesma cidade em que já moravam com a família, bem como à questão de fácil deslocamento e transporte. Como observado no mapa, a sequência segue até ao valor (V) "feliz comigo mesmo" e demonstra consequências que, apesar de não culminarem em valores, são importantes para ajudar a compreender a cadeia citada. A consequência "não perder tempo" refere-se ao deslocamento de ir para a faculdade, e a consequência "família" relaciona-se ao fato de que a proximidade de casa ajuda muito na questão financeira familiar, uma vez que, assim, não há gastos a mais com moradia, alimentação e outros (o que ocorreria se os estudantes fossem para outra cidade).

Dessa forma, percebe-se nessas relações elementos de cunho utilitário identificados nas consequências, como a proximidade de casa com a faculdade, a questão financeira, a economia de tempo e a proximidade dos familiares. Tais consequências, por sua vez, culminam no valor "feliz comigo mesmo", assumido, aqui, um caráter hedônico.

Nas relações estabelecidas anteriormente, é possível comprovar que a decisão por um curso em uma faculdade tomada pelos estudantes está ligada a uma visão de curto e longo prazo. Trata-se do que Ehrenberg e Smith (2000) atribuem ao estilo de vida de estudantes (importância em curto prazo), que seria a economia por ainda morarem com a família, ao desfrute que o ensino superior pode proporcionar (importância em longo prazo), ligado à competência, para atingirem valores como felicidade consigo e realização.

Outras sequências a serem mencionadas,não dominantes, porém completas, são: $(A)$ "indicação e referência de outras pessoas" - (C) "ter bons professores e oportunidade de estágio" - (V) "feliz comigo mesmo" e (A) "nome e estrutura da faculdade" - (C) "ser competente" - (V) "realização" ou (V) "feliz comigo mesmo". Tais sequências partem de atributos diferentes, que, 
no entanto, culminam no mesmo valor de hedonismo de Schwartz. Cabe salientar a importância da consequência "ser competente", que se destaca como central na análise das cadeias.

As cadeias mais fracas podem refletir aspectos importantes a serem analisados, já que podem caracterizar algo de real importância para os detentores do serviço em relação ao mercado, mas que não se faz presente na percepção dos consumidores, devido à fraca relação entre as cadeias ou ao pouco conhecimento do público entrevistado. No mapa, além de cadeias mais fracas, encontramse, em algumas situações, ladders (encadeamentos A-C-V) que não foram concluídas, não chegando ao nível mais alto de abstração. Do atributo (A) "nome e estrutura da faculdade" parte (C) "base profissional", já que, conforme os entrevistados, estar em um lugar com nome e estrutura irá lhes dar base profissional. Percebe-se a dificuldade dos alunos em determinar como seria tal base profissional e abstrair até um valor. Para os estudantes, o atributo seria muito forte, de modo que o nome e a estrutura dariam chances de uma formação profissional. Evidencia-se, ainda, a presença de (C) "sentir confiança e segurança", quando atribuem ao nome e à estrutura da faculdade a calma e confiança necessária na hora de fazer estágio. Desse modo, o nome e a estrutura que a faculdade possui dão aos alunos algum tipo de segurança no âmbito profissional da Enfermagem.

Outra cadeia não completa foi a que partiu de $(A)$ "indicação e referência de outras pessoas" para (C) "maior aprendizado", o que demonstra que a influência de quem cursa ou já cursou a faculdade gera a confiança, a partir da indicação e referência de ex-alunos, da certeza de um maior aprendizado na instituição em questão. Nesse ponto, identifica-se o quanto a segurança é importante para os entrevistados, confirmado pelo que Veinstein (1994) coloca a respeito da escolha, que envolve mudanças, perdas e medo.

Por fim, a sequência (A) "próximo a minha casa" - (C) "questão financeira" - (C) "não perder tempo" demonstra uma relação que representa a facilidade que os alunos têm de morar em casa ou próximo a ela e de não gastarem seu tempo e dinheiro com deslocamento ou tarefas de casa, como alguém gastaria caso morasse sozinho ou em república; logo, possuem mais tempo para estudar. Já a sequência (A) "próximo a minha casa" - (C) "questão financeira" - (C) "família" evidencia que os entrevistados, por estarem perto de casa e ainda economizarem, decidem ficar perto da família e, assim, obterem sua ajuda. Desse modo, o lugar de pertencimento, na teoria por Bohoslavsky (1977), mais uma vez é importante para os alunos, tanto quanto o fato de estar perto da família como uma forma de construção da identidade profissional e pessoal-famliar.

A partir de uma análise final do mapa hierárquico de valores, observa-se que os atributos que chamam atenção são "próximo a minha casa" e "indicação e referência de outras pessoas", de onde partem as cadeias dominantes. Cabe destacar mais uma vez a forte relação, a mais alta identificada no mapa, entre o atributo "próximo a minha casa" e a consequência "questão financeira".

Em relação às consequências, destaca-se "ter bons professores e oportunidade de estágio" e "ser competente" pela centralidade e pelas ligações que as mesmas possuem no mapa. $O$ valor mais relevante seria o "feliz comigo mesmo" (ou hedonismo segundo Schwartz), pois é nele que várias consequências chegam e onde se encontram as cadeias dominantes. É interessante notar que, apesar de culminar em um valor hedônico, os fatores ou as consequências mais representativas encontradas são elementos utilitários, refletindo meios utilitaristas para o alcance dos valores mais hedônicos, indicados pelos entrevistados.

Os resultados apresentados permitem o desenvolvimento do marketing educacional na perspectiva de Manes (1997), tendo em vista a elucidação das necessidades, dos atributos e das consequências que atendem a tais necessidades e de seu respectivo valor, relacionado a cada relação (A-C-V) estabelecida. Assim, confirma-se a utilização da Teoria da Cadeia Meios-Fins como ferramenta gerencial, tal como preveem Borges et al. (2012), Figueiró et al. (2012) e Vilas Boas et al. (2005). 


\section{CONSIDERAÇÕES FINAIS}

Este trabalho teve como objetivo compreender que aspectos, considerando atributos, consequências e valores pessoais, norteiam o comportamento de estudantes no momento de escolha pelo curso de Enfermagem em uma IES. Em se tratando de um estudo sobre consumo, em uma perspectiva de valores, esta investigação utilizou a Teoria da Cadeia Meios-Fins e a técnica de escalonamento laddering. $\mathrm{O}$ emprego sistemático dessas abordagens permitiu a construção de um mapa hierárquico de valores (HVM), que foi interpretado e analisado visando compreender a estrutura cognitiva dos estudantes.

Um aspecto que ficou evidente no mapa de valores dos estudantes foi que a orientação de percepções parece seguir, predominantemente, para a direção do valor de "feliz comigo mesmo", segundo os entrevistados. As conexões mais fortes entre atributos, consequências e valores ou cadeias dominantes resultaram nesse valor, que se enquadra em um domínio motivacional de natureza individual, em que o alcance da concretização de um sonho e o sucesso profissional refletem diretamente no próprio estudante.

Outra conclusão a qual se pode chegar foi a questão dicotômica dos objetivos de curto e longo prazo dos estudantes, que visam, respectivamente, atender às necessidades financeiras próprias e da família e adquirir competência e estabilidade futura. Além disso, verificou-se que os meios são extremamente utilitários para fins hedônicos.

Desse modo, percebe-se que o método adotado na perspectiva de valores pessoais dá base para o emprego do marketing educacional, contribuição teórica à área e embasamento para um perfil do consumidor por meio de seus valores na escolha por um serviço educacional, além de constituir um instrumento para a elaboração de melhor planejamento para a conquista e manutenção dos consumidores.

As informações contidas nas cadeias dominantes e no mapa hierárquico, por si só, já remetem a implicações gerenciais (VILAS BOAS, 2007), sobretudo, para o desenvolvimento de estratégias de marketing condizentes com as expectativas dos estudantes. Nesse contexto, desenvolver estratégias eficazes de segmentação de mercado, de posicionamento e, principalmente, de comunicação são algumas das possibilidades que podem derivar deste trabalho.

Desse modo, o fato de a proximidade de casa ser levada em conta pelos entrevistados dá base para ações que valorizem os estudantes da cidade e da região como principais públicos-alvo. Tomando como base ainda as cadeias dominantes, percebe-se que o marketing boca a boca é uma das formas que mais influenciam a decisão dos estudantes, o que torna necessária uma aproximação de ex-alunos e alunos com campanhas de marketing voltadas também para o público interno. Ressalta-se, também, que as consequências "ter bons professores e oportunidade de estágio" e "ser competente" tiveram centralidade no mapa, demonstrando que são aspectos que precisam da devida atenção da instituição de ensino no sentido de promovê-los e ressaltá-los em suas estratégias de comunicações com os estudantes.

Apesar de o presente estudo abarcar somente uma instituição pesquisada, com um público jovem e não possibilitar generalizações, este estudo compreende uma importante ferramenta para profissionais de marketing, podendo esses se apoiarem nas relações fortemente mencionadas pelos estudantes para a escolha do curso de Enfermagem em determinada instituição de ensino para elaborarem estratégias de marketing mais eficazes. 


\section{REFERÊNCIAS}

BOHOSLAVSKY, R. Orientação vocacional: A estratégia clínica. São Paulo: Martins Fontes, 1977.

BORGES, G. F. et al. Valores pessoais de idosos usuários de academias: uma análise sob a perspectiva da teoria da cadeia meios-fim. In: ENCONTRO NACIONAL DOS PROGRAMAS DE PÓS-GRADUAÇÃO EM ADMINISTRAÇÃO, 36., 2012, Rio de Janeiro. Anais... Rio de Janeiro: ANPAD, 2012. 1 CD ROM.

CARAPARA, A.; LANDIN, L. P. Etnografia: uso e potencialidades e limites na pesquisa em saúde. Interface - Comunicação, Saúde, Educação, São Paulo, v.12, n.25, p. 363 - 375, abr./jun.2008.

CHURCHILL, G. A. J.; PETER, J. P. Marketing: criando valor para os clientes. 2 ed. São Paulo: Saraiva, p. 626, 2000.

COBRA, M.; BRAGA, R. Marketing Educacional: ferramentas de gestão para instituições de ensino. São Paulo: Cobra Editora, p.184, 2004.

COSTA, F. J.; OLIVEIRA, L. G. L.; Valor percebdio no curso, percepção do prestígio e identificação com a profissão: Uma análise junto a estudantes de Administração e Contabilidade. Revista de Administração da UFSM, Santa Maria, v. 1, n.3, p. 453-468, set./dez. 2008.

DINIZ, D. M.; CASTRO, J. M. Processo de Gestão Estratégica em Universidade Privadas: um estudo de casos. Revista de Administração da UFSM, Santa Maria, v.3, n. 3, p. $311-325$, set./dez.2010.

EHRENBERG, R.; SMITH, R.S. A moderna economia do trabalho: teoria e prática pública. São Paulo: Makron Books, 2000.

FIGUEIRÓ, P. S. et al. Motivações e Valores Determinantes para o Consumo de Alimentos Orgânicos. In: ENANPAD, XXXVI, 2012, Rio de Janeiro. Anais... Rio de Janeiro, set., 2012.
GUTMAN, J. A means-end model for facilitating analysis of product markets based on consumer judgement. Advances in Consumer Research, v. 8, p. 116-121, 1981.

GUTMAN, J. A means-end chain model based on consumer categorization processes. Journal of Marketing, Chicago, v. 46, p. 60-72, abr. 1982.

GUTMAN, J. Exploring the nature of linkages between consequences and values. Journal of Business Research, v.22, p.143-148, 1991.

IKEDA, A.A.; VELUDO-DE-OLIVEIRA, T.M.; A teoria de meios-fim: uma aplicação em marketing educacional. FACES R. Adm, v.5, n. 1, p11-25, jan/abr., 2006.

IKEDA, A.A.; VELUDO-DE-OLIVEIRA, T.M. O conceito de valor para o cliente: definições e implicações gerenciais em marketing. Revista Eletrônica de Administração. ed 44, v.11, nำ2, mar./abr, 2005.

KOTLER, P. Administração de Marketing. 10ạ. Ed. São Paulo: Prentice Hall, 764p.,2000.

KOTLER, P.; FOX, K. F. A. Marketing estratégico para instituições educacionais. São Paulo, Ed. Atlas, p.444,1994.

LEÃO, A. L. M. S.; MELLO, S. C. B. Conhecendo o "valor do cliente" de um jornal on-line. Revista de Administração de Empresas (RAE), v.43, n.3, p.22-35, jul./set. 2003.

LOVELOCK, C. H. Classifyng service to again strategic insights. Journal of Marketing, v. 47, n. 3, p. 9-20, 1983.

MANES, J. M. Marketing para Instituições Educativas. Barcelona: Granica, 1997.

MARTINS, J.M.D.; TEIXEIRA, L.A.A.; SILVA, J.T.M.; Marketing educacional: uma análise de atributos e posicionamento de instituições de ensino superior. Revista do Mestrado 
em Administração e Desenvolvimento Empresarial, v. 13, n. 1, p. 57-75, 2009.

MEC - MINISTÉRIO DA EDUCAÇÃO. Apresenta informações sobre o Ministério da Educação, incluindo dados sobre instituições de ensino superior. Disponível em: <http://portal.mec. gov.br/ index.php>. Acesso em: 30 de janeiro de 2012.

NOGUEIRA, C. M. et al. Valores pessoais e percepção de atributos dos estudantes de medicina veterinária em uma instituição de ensino superior. In: ENCONTRO DE MARKETING DA ANPAD, 5., 2012, Curitiba. Anais... Curitiba: Anpad, 2012. 1 CD ROM.

OLIVEIRA, B; TAVARES, G. R. M; SATO, K. S. Percepção: uma caixa preta para Marketing?. Revista de Administração da UFSM, Santa Maria, v.3, n. 3, p. $424-430$, set./dez.2010.

PIMENTA, M. L.; VILAS BOAS, L. H. B. Percepções de consumidores de alimentos orgânicos na cidade de Uberlândia na perspectiva de valores: Uma aplicação da laddering e cadeia de meios e fins. In: ENCONTRO DE MARKETING DA ANPAD, 3., 2008, Curitiba. Anais... Curitiba: Anpad, 2008. 1 CD ROM.

PIMENTA, M. L. et al. Valores pessoais e percepção de atributos em marcas regionais de café na cidade de Lavras. Revista de Administração da UFSM, v.4, n.1, p. 39-52, jan./abr. 2011.

PINESE, H. P.; MORIGUCHI, S. N. Os valores pessoais que orientam o comportamento de jovens universitários como investidores da bolsa. In: ENCONTRO DE MARKETING DA ANPAD, 5., 2012, Curitiba. Anais... Curitiba: Anpad, 2012. 1 CD ROM.

REYNOLDS, T. J.; GUTMAN, J. Laddering theory, method, analysis and interpretation. Journal of Advertising Research, New York, v. 28, n. 1, p. 11-31, fev./mar. 1988.

REZENDE, R. C.; CAIXETA, R. P.; MORIGUCHI, S. $N$. Percepção de valor em educação superior pública: um estudo empírico com os alunos ingressantes no curso de Administração. In: ENCONTRO DE MARKETING DA ANPAD, 4., 2010, Florianópolis. Anais... Florianópolis: Anpad, 2010. 1 CD ROM.

ROKEACH, M. Crenças, atitudes e valores. Tradução de Angela Maria Magnan Barbosa; revisão técnica de Helmunt Ricardo kruger. Rio de janeiro: Ed. Interciência, 1981.

SERRALVO, F. A.;IGNÁCIOC.P.Ocomportamento do consumidor de produtos alimentícios: um estudo exploratório sobre a importância das marcas líderes. In: SEMEAD - Seminário em Administração FEA - USP, VII, 2004, São Paulo. Anais... São Paulo, 2004.

SCHWARTZ, S. H.; BILSKY, W. Toward a universal psychological structure of human values. Journal of Personality and Social Psychology. vol. 53, n. 3, p. 550-562, 1987.

SCHWARTZ, S. H. Universals in the content and structure of values: theory and empirical tests in 20 countries. Advances in Experimental Social Psychology. New York, v. 25, p. 1- 65. 1992.

TAMAYO, A.; PORTO. JB.B. Valores e Comportamentos nas Organizações. Petrópolis, RJ: Vozes, p.33-34, 2005.

VEINSTEIN, S. B. G. La elección vocacional ocupacional: Estrategias - técnicas. Buenos Aires: Marymar, 2ed.,1994.

VELUDO-DE-OLIVEIRA, T. M.; IKEDA, A. A. Valor em serviços educacionais. RAE- eletrônica, v.5, n.2, art. 12, jul./dez. 2006.

VILAS BOAS, L. H. B. et al. Compreendendo valores para consumidores orgânicos: uma análise sob a óptica da Teoria de Cadeias de Meios e Fins. In: Congresso da SOBER, XLIII, 2005, Ribeirão Preto. Anais..., jul., 2005.

VILAS BOAS, L. H. B. Perspectivas de segmentação para o mercado de produtos orgânicos com base na estrutura de valores. In: 
ENANPAD, XXXI, 2007, Rio de Janeiro. Anais... Rio de Janeiro, set., 2007.

VILAS BOAS, L. H. B. et al. Comportamento do consumidor sob a ótica da teoria meiosfim: Um estudo sobre os valores pessoais dos discentes do curso de especialização em gestão pública. In: ENCONTRO DE MARKETING DA ANPAD, 5., 2012, Curitiba. Anais... Curitiba: Anpad, 2012. 1 CD ROM. 